\title{
Relating the Library to the Classroom: Some Specific Suggestions
}

Mr. Williamson is a fellow at the Graduate Library School, University of Chicago.

A MAJOR item in our library faith has been the concept of the library as an integral part of the academic institution. We have worked so hard to sell that idea that we have not paused long enough really to take in the fact that we have won our point. Leading educators and accrediting agencies have accepted the principle that the library should occupy a central place in our colleges. Now we are on the spot.

We have sold good library service as essential to good instruction. As a result, we are faced with the necessity to provide that kind of service. The urgency of this need was pointed up by the proposal of William G. Land that, since the moment when student meets book is so important, the job of catalyst must be taken over by a group of subject specialists, leaving librarians to do the tasks of acquiring, processing, and housing the collection. ${ }^{1}$ To put it bluntly, we must do this job which we have sold as vital or we shall find it in other hands. There are many real objections to the Land proposal, but the only final answer will be library service closely related to the classrooms of the institutions we serve. We need to devote a great deal more time and attention to this phase of our work since it is the fundamental reason why academic libraries exist.

1 Land, William G. "The Functional College Library." Journal of Higher Education, $18: 90-9 \mathrm{I}$, February 1947 .
The greatest success in this field seems to be found in those institutions which have developed plans of education placing emphasis on individual instruction. Since most of us do not work in the Bards and Benningtons, however, a program of service for the more conventional kinds of schools may be discussed. Although the individual items for action are probably not new to you, an organized statement of plans and procedures designed to accomplish the prime objective may be useful. It may be emphasized that what is needed is a planned program carried out with continuity.

The first step in our planning should certainly be to examine the setting to which our library must adapt itself. How many students and faculty members do we serve? What is their composition in such things as age, sex, background, and major field of interest? What are the curricular offerings of the school? What are its objectives? What is the background and tradition of the college? These and similar considerations will affect our program.

Having examined the setting, we need to look at the library itself. We will want to know that it is adequate in all of its routines of ordering, processing, and circulating the materials of the collection. The housekeeping details must be well in hand so that, if our service program is successful, we can satisfy the demand.

In implementing the plan, we will want to see that, so far as possible, our organization, staff, and building are adapted to the job. Depending upon local campus condi- 
tions, we may want to consider classroom collections, departmental libraries, and dormitory libraries. We may adopt a subject-divisional arrangement.

Regardless of the organizational set-up chosen, the staff should consist of individuals who are personally effective and whose qualifications include an understanding of educational problems. They should be recognized as full-fledged faculty members as a basis for establishing cooperative and mutually helpful relations with classroom teachers. The whole public service staff should be large enough so that, especially at reference advisory points, thoughtful personal attention can be given to each individual problem. Every member of the staff should keep in touch with curricular use of the library by working at a public service desk part of the time. And we venture to say that this applies also to the chief librarian. We need to have enough people so that some time can be spent on planning, improving, and coordinating rather than simply in fulfilling a heavy schedule of work at service points. One organizational device to provide for the necessary over-all planning is the position of supervisor of public services.

The success of the program will depend to some extent on the adequacy of the building which, so far as possible, should have individual study facilities for students and faculty, conference rooms where the instructor can meet his students, and space in which whole classes can meet. Attention needs to be given to the conditions such as color, lighting, and ventilation which make the library an attractive place for work. Certainly students should have direct access to books.

This whole program has the one overriding purpose of bringing library and classroom closer together, but the individual items for action are designed to do specific things. We have divided them on this functional basis. These specific purposes are (I) to give the librarians information about the classroom (2) to keep the service responsive to curricular needs (3) to stimulate students to use that service and (4) to inform the classroom teachers about the services and collection of the library.

First, activities which give the librarians information about the classroom.

Opportunities should be sought for librarians to keep in touch with current classroom developments by visits to classes and to departmental meetings. Regular attendance at faculty meetings and service on committees can, in addition, keep the librarians informed of future curricular plans. Conferences with individual faculty members can be helpful but are usually most successful when initiated in response to an evident need. When course syllabi are available, their use can be an excellent source of classroom information. One of the most promising devices for getting information is a departmental library representative. This person can be either a member of the library staff or a member of the department, although the latter is probably preferable. This method will succeed only if the individual chosen is interested and vigorous and has the active support of his department head. In courses which have unusually heavy library use, a student course representative can help to keep information flowing to the library and to get the cooperation of the other students in the use of books.

Second, activities to keep the service responsive to classroom needs.

There should be provisions for rush cataloging of books which are needed urgently. There should be arrangements for a wait- 
ing list for books in great demand and for locating books requested but not accounted for. A device which may be helpful in measuring and meeting heavy demand is what might be called a best seller list. That is, the supervisors of the main book service desks report at regular intervals the books which they have been unable to supply because of a lack of sufficient duplicates. The record of these reports provides a history of demands over a long period. Orders for duplicate copies are then considered on the basis of that record. This procedure allows the duplication of books in response to observed need and avoids unwise duplication based on a heavy demand at only one time. Similar services can be provided for periodicals. The perennial irritation of magazines being in the bindery probably cannot be entirely eliminated. Many times, however, volumes which are being prepared for the bindery are still in the building though not in their normal location. We must provide means for keeping track of these volumes and for making them available.

\section{Third, activities to encourage students to} use the library.

The first essential is teaching the methodology of library use. If individual teaching is impossible, this instruction can best be given in connection with courses within the subject departments so that the students can see an immediate and practical use for the techniques taught. ${ }^{2}$ The logical place for the basic instruction is the Freshman English course. After that time, instruction should be given in the many advanced classes which need information on essential reference tools in their field, fundamental bibliographies like the L C Author Catalog and Subject Catalog and the C.B.I., and

\footnotetext{
2 Brown, Helen M. "The Librarian as Teacher in the College Library." College and Research Libraries, Io: I 9 -I 23, April r 949.
}

other matters helpful to them. The trick, of course, is to get the class instructors to provide the necessary time. Opportunities for individual instruction are offered in connection with interlibrary loan service and the frequent contacts with students provided by reference service. Closely related to library instruction is a handbook on the library and its essential services.

Having instructed students in the use of the library, we need to call their attention to the resources of the collection. The library can offer to take books to classrooms for comment and display in preparation for some specific assignments or for general reading in the course subject. Book jackets may be displayed outside the library and, within the building, offer attractive and purposeful decoration. A display shelf of new books at the circulation desk can encourage book interest as can a browsing room.

Exhibits can be an important help. There is a legitimate place for exhibits on general subjects such as the structure of the United Nations, but this medium also can be related directly to the curriculum. If a new course sequence such as an American Civilization program is instituted, an exhibit on the new Papers of Thomas Jefferson $^{3}$ can be related to that program. More closely tied in with individual courses would be exhibits, for example, on the steps in writing a term paper in connection with freshman library lectures or on Columbus in connection with American history courses. To serve the library directly, one could set up an exhibit on types of book mutilations with appropriate comments.

In addition to teaching students how to use the library and calling their attention to the books in the collection, we need to take every opportunity to keep the library before

\footnotetext{
${ }^{3}$ Boyd, Julian P., ed. The Papers of Thomas Jefferson. Princeton, Princeton University Press, 1950-.
} 
the college community and to develop means of contact with students. The resultant publicity and good feeling will foster use of the library. A Student Library Committee as reported by Stokes $^{4}$ can serve to encourage interest in the library. It can provide a channel for obtaining student points of view on the quality and irritations of library service. This group can help to support the library in instituting new plans of service and in enforcing necessary regulations.

The major medium for publicity is the campus newspaper either through a regular column or through regular stories in the paper. There are many different topics about the library which are newsworthy and these should be exploited. A good deal of grief can be avoided by putting the essential facts in writing for the student reporters to translate into journalistic style. At least the names may be spelled right even if the rest of the story is garbled. The library can sponsor or encourage book discussions, forums, and meetings of all kinds in the building. Library clubs, teas, open houses, and such functions have been frequently reported as valuable.

\section{Fourth, activities designed to reach and in- form the classroom teachers.}

The whole program can stand or fall depending upon the success of this phase of it. It is unfortunately true that students will be all too glad to stay away from the library if their instructors make it possible for them to do so. Therefore, our major efforts must be directed toward the classroom teachers. Since many of them are jealous of their prerogatives, care and tact are required in this realm.

We must gain the confidence of the group in our abilities and in our interest. The

"Stokes, Katherine M. "Selling the College Library's Services." College and Research Libraries, 4:120-27, March I 943. library staff members must have qualifications comparable to those of classroom teachers. Attendance at faculty meetings, membership in the local A.A.U.P. chapter, and participation in the official affairs of the college demonstrate both librarians' interest and their professional responsibility. Personal friendships and social contacts make consultations easier and help understanding on both sides.

Especially in our relations with the other members of the faculty, we need to assert our confidence in the essential importance of our job and in our own competence to do that job. I have observed that we librarians have what might almost be called a psychopathic eagerness to be told our faults, especially by conference speakers. While we certainly want to benefit from constructive criticism, we need to show a quiet confidence in our essential contribution. This applies particularly to our own college if we expect to keep our place as faculty colleagues.

While underrating our own capacities, we sometimes overrate the knowledge of the classroom teachers by taking it for granted that they know all the fundamentals of the library. This assumption is not always justified. Some of them do not know of the existence of tools which are important to all fields such as the LC printed catalogs, P.T.L.A., and the C.B.I. When it comes to a more esoteric record like the shelflist, even the most informed and library-minded faculty members may be ignorant of its existence and of its value to them in making a survey of the collection. These are only samples of the lack of information to which we should be alert. They indicate the need for a program of education about the library directed to the departmental teachers.

These people need especially to understand that books must be processed carefully 
so that the catalog will be maintained at a high standard as a key to the book collection. The resultant lag between arrival of books and their availability is all too $t$ often a source of considerable friction, part of which can be eliminated by a genuine understanding of the reasons. This area of library operation is in need of a thorough re-examination to see if our standards are not too high and our processing inefficient in light of new developments. We must be sure that the time lag is necessary before we try to explain it.

Some of the channels for educating the faculty have already been mentioned in other connections. Faculty meetings offer opportunities for attractive displays which can unobtrusively help to inform the faculty members about library matters. Departmental meetings can occasionally be devoted to the library in relation to the particular department. Library publications provide media for statements and explanations of all kinds. An orientation in the library is especially desirable for instructors newly joining the faculty. Individual conferences with instructors, so often the outgrowth of problems and complaints, can be used constructively to give information and to foster understanding.

The classroom teachers need to know what books are in the collection if they are to suggest titles to their students. They should be notified when books arrive if they have recommended them or if they have special reason to be interested in them. A regular list of new acquisitions is essential and should be sent to each faculty member as well as being posted widely. If school is in session in the summer, absent faculty members will appreciate having the lists saved for them until the fall. A personal letter to accompany the package will further enhance the value of this service. Notices of periodical articles of interest should be sent to various department members.

The reserve book system causes such common problems that it warrants special mention. One perennial problem is getting reserve lists soon enough that the books can be ready before assignments are made. A practical solution is to compare the record of previous reserve lists with the schedule of courses to be offered in the new term. A phone call to the instructors concerned will then bring results where a general announcement or a form letter will not. After the list is obtained, the instructor should be notified as soon as his books have been put on reserve. When the course has been completed, he should be informed how much these books have been used. He can benefit by this information in revising his list and in planning his presentation of the subject matter the next time the course is offered. This report may encourage him to limit his reserves to those books which have been sufficiently used. A simple means of reporting is provided in merely sending the reserve book cards to the instructor when the course is completed. They should be accompanied by a letter explaining possible uses of the information on the cards.

These then are the major purposes of our program to relate the library to the classroom. We must keep up with what is happening in the classes, we must make our services responsive to curricular needs, we must stimulate the students to use those services, and we must let the classroom teachers know what is going on in the library. We have suggested a few ways of doing these things. None of these methods is sufficient in itself, but when carried out regularly as part of a planned program, they can produce a cumulative effect greater than the sum of the parts. We must develop new and better methods and let each other know about successful developments through our journals and through meetings. 